\title{
Enhancement of activated sludge dewatering performance by combined composite enzymatic lysis and chemical re-flocculation with inorganic coagulants: Kinetics of enzymatic reaction and re- flocculation morphology
}

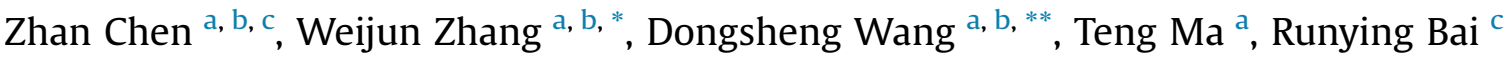 \\ a School of Environmental Studies, China University of Geosciences, Wuhan 430074, China \\ b State Key Laboratory of Environmental Aquatic Chemistry, Research Center for Eco-Environmental Sciences, Chinese Academy of Sciences, Beijing 100085, \\ China \\ c School of Civil Engineering, Inner Mongolia University of Technology, Hohhot 010051, China
}

\section{A R T I C L E I N F O}

\section{Article history:}

Received 21 May 2015

Accepted 17 June 2015

Available online 20 June 2015

\section{Keywords:}

Waste activated sludge

Enzymatic treatment

Extracellular polymeric substances

Inorganic salt coagulants

Floc morphology

Sludge dewatering performance

\begin{abstract}
A B S T R A C T
The feasibility of combined process of composite enzymatic treatment and chemical flocculation with inorganic salt coagulants was investigated in this study. The evolution of extracellular polymeric substances (EPS) distribution, composition and morphological properties were analyzed to unravel the sludge conditioning mechanism. It was found that sludge filtration performance was deteriorated due to release of a large amount of biopolymers after enzymatic treatment. The change in EPS followed the pseudo-first-order kinetic equation well under enzymatic treatment. The feeding modes of enzymes had a significant influence on sludge lysis efficiency under compound enzymes treatment. Alpha amylase + protease was more effective in solubilization than other two addition modes (protease $+\alpha-$ amylase or simultaneous addition). The sludge floc re-formed and macromolecule biopolymers were effectively removed through coagulation process. At the same time, both of filtration rate and cake solid content of sludge treated with enzymes were improved with increasing dosage of coagulants, and ferric iron $\left(\mathrm{FeCl}_{3}\right)$ had better performance in sludge dewaterability enhancement than polyaluminium chloride (PACl). In addition, sludge filtration property was slightly deteriorated, while the cake moisture reduction was favored at the optimal dosage of inorganic coagulants.
\end{abstract}

(c) 2015 Elsevier Ltd. All rights reserved.

\section{Introduction}

The management of wastewater sludge, now, often referred to as biosolids, accounts for a major portion of the cost of the wastewater treatment process and represents significant technical challenges. Waste activated sludge from secondary settling tank generally contains over $99 \%$ water. The regulation sheet on landfills issued by the Ministry of Housing and Urban-Rural Development in China demands a minimum dry solids content of $40 \%$ for unlimited incorporation of dewatered sludge from municipal wastewater treatment plants (WWTPs). Therefore, the development of high

\footnotetext{
* Corresponding author. School of Environmental Studies, China University of Geosciences, Wuhan 430074, China.

** Corresponding author. School of Environmental Studies, China University of Geosciences, Wuhan 430074, China.

E-mail addresses: zhwj_1986@126.com (W. Zhang), wgds@rcees.ac.cn (D. Wang).
}

performance dewatering processes has been the most important research areas of environmental science and technology. In general, the moisture in sludge system can be classified into free water (accounted for about 70\%), interstitial water (about 20\%), adsorbed water (about 7\%) and bound water (about 3\%) (Vaxelaire and Cezac, 2004). Except for sludge properties, the dewatering performance was mainly dependent on selection of sludge devices and chemical conditioning methods.

Extracellular polymeric substances (EPS) account for about $60-80 \%$ of total sludge mass (Liu and Fang, 2003) and significantly affect other sludge physicochemical property, such as surface charge, floc stability and rhetorical behavior (Mikkelsen and Keiding, 2002). Many previous studies have demonstrated that EPS was the most crucial deciding factor for sludge dewatering (Mikkelsen and Keiding, 2002). Houghton et al. (2001) reported that the dewaterability was determined by the contents of EPS and there existed an optimal EPS content for each sludge, at this time, which exhibited the best dewatering property. Many researchers 
found that EPS composition (proteins and polysaccharides ratios) have more significant effects on sludge dewaterability (Higgins and Novak, 1997). Murthy and Novak (1999) reported that high proteins/polysaccharide ratio was detrimental for sludge dewatering performance. More recently, EPS was found to have double layers including the loosely bound EPS (LB-EPS) which is diffused from the tightly bound EPS (TB-EPS) that surrounds the cells (Poxon and Darby, 1997; Ramesh et al., 2006; Li and Yang, 2007). Moreover, some researchers reported that only the LB-EPS was related to the sludge dewaterability (Ramesh et al., 2006; Li and Yang, 2007; Raynaud et al., 2012). Yu et al. (2008) suggested that sludge floc was composed by five fractions: supernatant, slime, LB-EPS, TBEPS, and pellet, and the sludge dewatering performance was mainly dependent on the soluble EPS characteristics.

In general, it is essential to precondition the sludge particles with chemicals properly before the dewatering in order to improve the operating performance. For example, addition of inorganic or organic flocculants can agglomerate fine sludge colloids to form large flocs through charge neutralization and bridging, which can be more easily separated from the water (Niu et al., 2013; Zhang et al., 2014). EPS fraction in activated sludge was highly hydrated, and the traditional chemical flocculants was ineffective to destroy EPS structure and convert bound water into free water. Therefore, the advanced sludge technologies (AST) were developed to improve sludge dewatering property and cake solid content by solubilizing EPS components (Neyens et al., 2004). The established AST includes photo-Fenton/Fenton oxidation technology (Tokumura et al., 2007; Liu et al., 2013; Neyens and Baeyens, 2003), acid and alkali treatment (Zhu et al., 2013), heat treatment (Neyens et al., 2004), enzymatic treatment (Thomas et al., 1993) and integrated process.

Biological enzymes cannot solubilize the EPS components of activated sludge under mild conditions, but also improve its subsequent treatment and disposal. Therefore, enzymatic treatment is very promising technique in sludge treatment (Ayol, 2005). Initially, Thomas et al. (1993) found that addition of the enzymes could improve the mechanical dewatering in common filter press or decanters in combination with flocculation. Dursun et al. (2006) compared the sludge conditioning efficiency of enzymatic treatment in laboratory and pilot scale. The results revealed that a significant increase in cake solid content can be reached by adding enzymes at low dose. In practical application, it was found that no obvious improvement of final cake solid content was observed using centrifuge as dewatering equipment, which can be attributed to floc deterioration in the high shear applied in centrifugation. Ayol (2005) reported that the enzyme additions enhanced dewaterability of the polymer conditioned samples in terms of CST and solids content of final product, demonstrating the possibility of significant volume reductions using enzymatic treatment at fullscale. Sesay et al. (2006) found that, with especially higher SRT values, extracting proteins was more effective after enzymatic treatment. In addition, Bonilla suggested that lysozyme aided in the flocculation of particles reducing the polymer demand from $11 \%$ to $6 \%$, and conditioning mechanism of lysozyme was similar to that of a flocculant (Bonilla et al., 2015).

Few of previous studies have investigated the feasibility of combined enzymatic treatment and chemical re-flocculation on dewatering performance. Especially, the evolution of EPS and morphological properties under chemical conditioning was still not clear. Thus, the objectives of this study were to: (1) investigate the effect of combined composite enzymatic lysis and chemical reflocculation on sludge dewatering performance; (2) deeply understand the dynamic variation in distribution and composition of EPS under enzymatic hydrolysis reaction; (3) optimize the addition modes and operating parameters of composite enzymatic treatment; (4) observe the morphological properties under combined conditioning process.

\section{Materials and methods}

\subsection{Waste sludge and reagents}

Waste active sludge was obtained from the Beixiaohe WWTP in Beijing city. This WWTP treats approximately $1,000,000 \mathrm{~m}^{3}$ daily by combined membrane bioreactor (MBR) and ozonation process. The sludge characteristics can be found in Table 1. The characteristics of neutral protease and medium temperature alpha amylase ( $\alpha$ amylase) can be found in Table 2. Both of them were purchased from Tianjin Noao Sci \& Tech Development Co., Ltd in China.

\subsection{Batch test}

\subsubsection{Enzymatic hydrolysis procedure}

$100 \mathrm{~mL}$ sludge was placed into Erlenmeyer flasks under magnetic stirring at optimal temperature. Then, the enzyme was added to initiate the reaction. After $4 \mathrm{~h}$ of reaction, sludge suspension was used for EPS and dewaterability measurement. With regard to kinetic test, sludge of $600 \mathrm{~mL}$ were put into $1 \mathrm{~L}$ Erlenmeyer flasks with mixing. After enzymes were added, $50 \mathrm{~mL}$ sludge samples were taken out and placed into centrifuge tubes at different time intervals within $6 \mathrm{~h}$. The reaction temperature for protease and $\alpha$ amylase were 45 and $55^{\circ} \mathrm{C}$ respectively.

\subsubsection{Chemical re-flocculation}

The sludge was mixed with a conventional jar-stirring device. Sludge samples of $500 \mathrm{~mL}$ in $1 \mathrm{~L}$ beakers were used in the experiments. The following mixing procedure was used: a rapid mix period for $30 \mathrm{~s}$ at $200 \mathrm{rpm}$ followed by a slow-stir phase at $50 \mathrm{rpm}$ for $10 \mathrm{~min}$. The coagulants $\left(\mathrm{FeCl}_{3}, \mathrm{PACl}\right)$ were added with agitation using a graduated finnpipette. At the end of mixing, the conditioned sludge was allowed to settle in the beaker for $30 \mathrm{~min}$. Finally, the floc morphology and soluble EPS were determined.

\subsubsection{Extraction of EPS}

A heat extraction method was modified to extract the LB-EPS and TB-EPS from the sludge (Liyun Ge and Luming, 2006). A sludge suspension was firstly dewatered by centrifugation in a $50 \mathrm{~mL}$ tube at $3000 \mathrm{~g}$ for $10 \mathrm{~min}$. The supernatant was collected as soluble EPS to analyze chemical oxygen demand (COD). The sludge pellet in the tube was then resuspended into $15 \mathrm{~mL}$ of $0.05 \% \mathrm{NaCl}$, sonicated at $20 \mathrm{KHz}$ for $2 \mathrm{~min}$, shaken horizontally at $150 \mathrm{rpm}$ for $10 \mathrm{~min}$ and sonicated again for an additional $2 \mathrm{~min}$. The liquor was centrifuged at $8000 \mathrm{~g}$ for 10 min to separate solids and supernatant. The collected supernatant was regarded as the LB-EPS. The residual sludge pellet left in the centrifuge tube was resuspended in a $0.05 \%$ $\mathrm{NaCl}$ solution, sonicated for $3 \mathrm{~min}$, then heated at $80^{\circ} \mathrm{C}$ for $30 \mathrm{~min}$, finally centrifuged at $12,000 \mathrm{~g}$ for $20 \mathrm{~min}$ to collect TB-EPS. The

Table 1

Characteristics of waste active sludge.

\begin{tabular}{|c|c|c|c|c|c|c|c|}
\hline Indicator & Moisture content (\%) & $\mathrm{pH}$ & VSS/TSS & $\operatorname{CST}(s)$ & $\mathrm{d}_{0.5}(\mu \mathrm{m})$ & Zeta potential $(\mathrm{mV})$ & $\mathrm{SCOD}(\mathrm{mg} / \mathrm{L})$ \\
\hline Value & 97.95 & 7.5 & 0.75 & 320 & 62 & -15.2 & 130 \\
\hline
\end{tabular}


Table 2

Characteristics of enzymes.

\begin{tabular}{|c|c|c|c|}
\hline Enzymes & Enzyme activity (U/g) & Optimum reaction $\mathrm{pH}$ range & Optimum temperature $\left({ }^{\circ} \mathrm{C}\right)$ \\
\hline Neutral protease & 200,000 & $7.0-8.0$ & $40-50$ \\
\hline$\alpha$-amylase & 4000 & $5.5-7.0$ & $50-80$ \\
\hline
\end{tabular}

membrane filter was used to remove the particulates in EPS samples prior to analysis. The concentrations of different EPS components were determined for COD.

\subsubsection{Determination of sludge dewaterability}

Since the determination of specific resistance to filtration (SRF) has the similar physical process to the high pressure dewatering, it was used to evaluate the sludge dewaterability in this work. The SRF was conducted in a $250 \mathrm{~mL}$ Buchner funnel using a filter with $0.45 \mu \mathrm{m}$ filter paper. The Buchner funnel was filled with $100 \mathrm{~mL}$ of the sludge suspension, and a constant pressure of 0.6 MPa was applied by an air pump. The volume of filtrate under pressure was continuously recorded every $10 \mathrm{~s}$ before surface cracking was detected. The SRF of the sludge was calculated by:

$r=\frac{2 P A^{2} b}{\mu \omega}$

where $\mathrm{P}\left(\mathrm{kg} / \mathrm{m}^{2}\right)$ is the pressure applied, $\mathrm{A}\left(\mathrm{m}^{2}\right)$ is the filter area, $\mu$ $\left(\mathrm{Kg} \cdot \mathrm{s} / \mathrm{m}^{2}\right)$ is the $\mathrm{KV}, \omega\left(\mathrm{kg} / \mathrm{m}^{3}\right)$ denotes dry solid weight per unit volume sludge on the filtrate media, $\mathrm{b}$ is the time -to-filtration ratio, which is the slope of the curve that is obtained by plotting the ratio of the time of filtration to the volume of filtrate $(t / V)$ versus the filtrate volume $(V)$

\subsubsection{Analytical methods}

COD was measured using HACH DR2800 spectrophotometer with 2 h digestion. Polysaccharide was determined by anthronesulfuric acid method with glucose as standard (Frolund et al., 1996). Protein was measured by Lowry-Folin method with bovine serum albumin (BSA) as standard (Frolund et al., 1996). The concentration of ammonia nitrogen was determined by Nessler's reagents spectrophotometer method according to APHA-AWWA (APHA, 1998). Three-dimensional excitation emission matrix (3DEEM) was measured by a Hitachi F-4500 fluorescence spectrophotometer with an excitation range from 200 to $400 \mathrm{~nm}$ and an emission range from 220 to $550 \mathrm{~nm}$. The spectra were recorded at a scan rate of $12,000 \mathrm{~nm} / \mathrm{min}$, using excitation and emission slit bandwidths of $5 \mathrm{~nm}$. The EPS samples were diluted by 200 times prior to EEM analysis. Other sludge parameters, including TSS, volatile suspended solids (VSS) were determined according to standard methods (APHA, 1998). pH was measured by a pHS-3C (Shanghai, China) pH meter.

Each jar test experiment was performed in duplicate. And each experimental parameters was analyzed in triplicate and the standard deviations of all analyses were always less than $5 \%$, unless noted in the text.

\section{Results and discussion}

\subsection{Effects of enzymatic treatment on sludge dewaterability}

As depicted in Fig. 1, with the increase of two enzymes addition, the sludge SRF decreased firstly and then increased. It reached the minimum of $7.47 \times 10^{13} \mathrm{~m} \mathrm{~kg}^{-1}$ and $1.34 \times 10^{15} \mathrm{~m} \mathrm{~kg}^{-1}$ when the dosage of protease and amylase were 50 and $100 \mathrm{mg} / \mathrm{gTSS}$. It was noted that SRF with $\alpha$-amylase treatment was much higher than

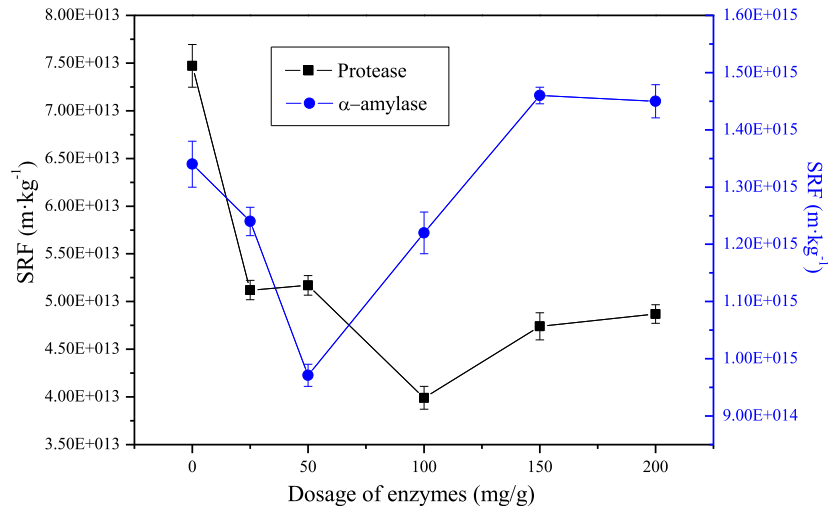

Fig. 1. Effect of enzymatic treatment on SRF.

that after protease treatment at the same dosage. According to the value of SRF, sludge can be classified into poor dewaterability $\left(>1 \times 10^{13} \mathrm{~m} \mathrm{~kg}^{-1}\right)$, medium dewaterability $\left(0.5-0.9 \times 10^{13} \mathrm{~m} \mathrm{~kg}^{-1}\right)$ and good dewaterability $\left(<0.4 \times 10^{13} \mathrm{~m} \mathrm{~kg}^{-1}\right)$ (Zhang et al., 2014). Thus, further treatment was needed to improve sludge dewatering property.

\subsection{Change in EPS properties under enzymatic treatment}

\subsubsection{Effects of enzymes dosage on EPS distribution and composition}

It can be seen from Fig. 2 (a) and (b) that the contents of SEPS and LB-EPS were significantly increased, while no obvious change in TB-EPS was observed under enzymatic treatment. Overall, hydrolysis efficiency of amylase was higher than that of protease. With addition of protease and amylase, SEPS content increased from 90 to $78 \mathrm{mgCOD} / \mathrm{gTSS}$ to 254 and $319 \mathrm{mgCOD} / \mathrm{gTSS}$ after $4 \mathrm{~h}$ of reaction. At the same time, LB-EPS was increased from 11 to 8.5 $\mathrm{mgCOD} / \mathrm{gTSS}$ to 52.5 and $46.5 \mathrm{mgCOD} / \mathrm{gTSS}$. It is interesting to note that the amylase exhibited higher protein solubilization efficiency compared to protease. The protein concentration in SEPS increased from $23.65 \mathrm{mgCOD} / \mathrm{gTSS}$ to $34.2 \mathrm{mgCOD} / \mathrm{gTSS}$ under protease treatment, while it increased from $45.5 \mathrm{mgCOD} / \mathrm{gTSS}$ to 72.9 $\mathrm{mgCOD} / \mathrm{gTSS}$ in $\alpha$-amylase hydrolysis. Furthermore, the protein content in TB-EPS was decreased somewhat after addition of enzymes. As presented in Fig. 2 (e) and (f), the contents of polysaccharides in SEPS and LB-EPS of sludge were significantly increased after enzymatic treatment. The results indicated that EPS was more readily to be extracted after enzymatic treatment, producing looser floc structure. It should be noted that simultaneous release of proteins and polysaccharides was observed with single enzyme addition and the change in protein content showed a similar pattern to that of polysaccharide. In fact, protein and polysaccharide in activated sludge always existed in the form of complexes (Dignac et al., 1998), so both of them were released simultaneously under single enzyme treatment. As mentioned above, the SRF of sludge with amylase treatment was higher than that under protease hydrolysis. This can be attributed to more effective sludge solubilization of amylase; especially the higher content of protein was released. Many studies have demonstrated 

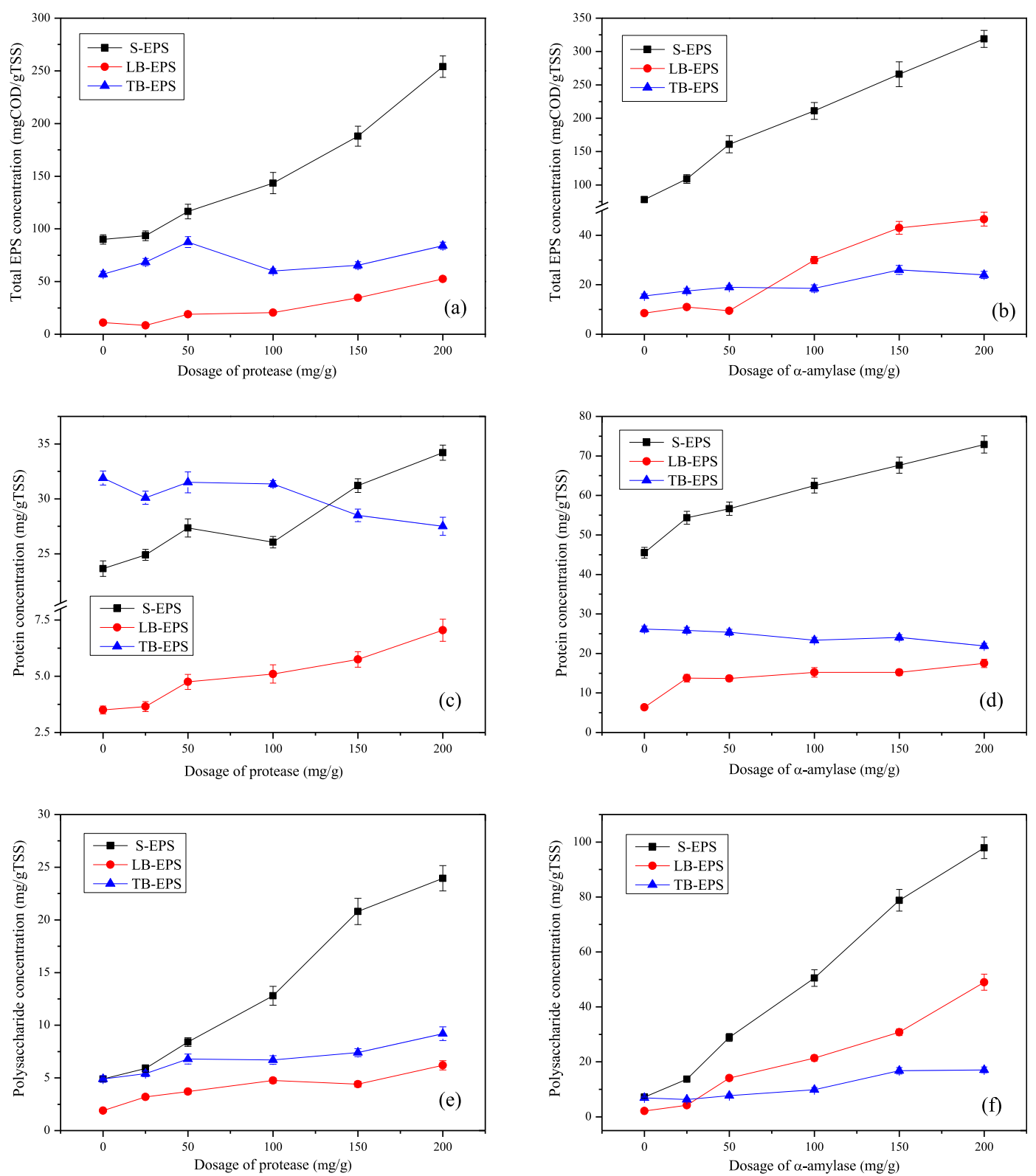

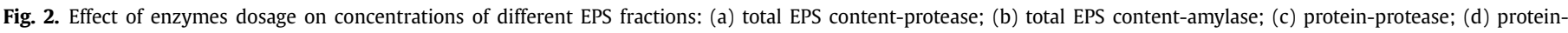
amylase; (e) polysaccharide-protease; (f) polysaccharide-amylase.

that sludge filtration property was mainly dependent on SEPS properties, and the high content of protein in SEPS was always detrimental to sludge filterability (Zhang et al., 2014, 2015a, 2015b).

\subsubsection{Enzymatic kinetics of different EPS components}

The variation in EPS properties with reaction time can be found in Fig. 3. The sludge was effectively solubilized by addition of two enzymes. Enzymatic treatment resulted in reduction of TB-EPS while significant increase in content of LB-EPS and SEPS, indicating that the TB-EPS was converted into LB-EPS and SEPS. Therefore, the sludge floc became looser, which can be confirmed by the fact that sludge settleability was deteriorated and particles were floated on the top of the centrifugal tubes after enzymatic treatment (see Fig. S1 of supporting information (SI)). It should be pointed out that each EPS component reached the equilibrium after $3 \mathrm{~h}$ of reaction under protease treatment, while the hydrolysis process still wasn't complete for amylase hydrolysis. This observation revealed that catalytic activity of amylase was more effective and lasting than protease in sludge solubilization.

Kinetic modeling (equations (2) and (3)) was used to get further insights into the kinetic variation in EPS characteristics under enzymatic hydrolysis.

$$
-\frac{d x}{d t}=K_{h} x
$$

$\ln x=K_{h} t+b$

Where, $K_{h}$ denotes the solubilization rate constant, $b$ is the intercept. By plotting $\ln x\left[\ln \left(C O D / C O D_{0}\right)\right]-t$, the slope and the intercept can be obtained.

The fitting results were given in Fig. 4 and Table 3. It can be seen that the sludge hydrolysis rate of $\alpha$-amylase was significantly higher than that of protease. This observation might be attributed 

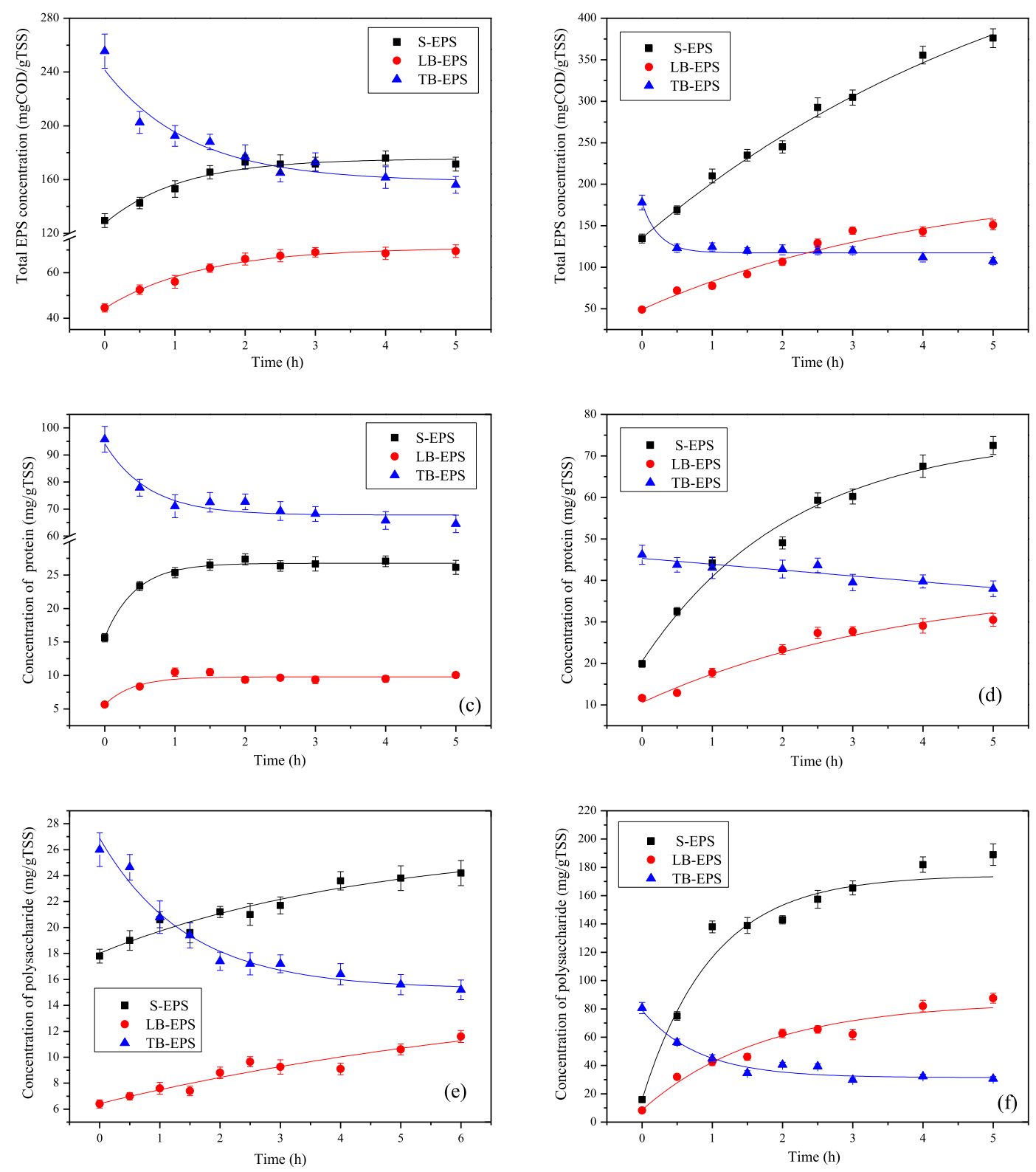

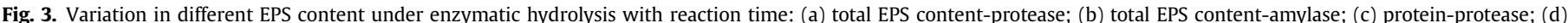

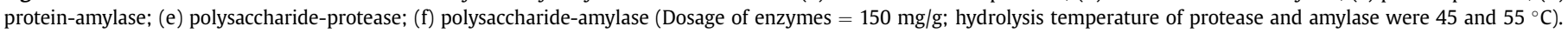

to two reasons. At first, the polysaccharide was more soluble and thus its solubilization rate was higher than protein-like substances. On the other hand, temperature had a synergistical effect in sludge solubilization, the sludge lysis was enhanced by increasing the reaction temperature (Yu et al., 2014). In addition, it is well known that the enzymatic hydrolytic reactions are very dependent on temperature, and the enzymatic treatment could be improved by increasing reaction temperature (Sesay et al., 2006). Almost all cell reactions are affected by temperature, and high temperature may break the cell structure. This phenomenon could be explained according to the amended Arrhenius equation:

$k=A e\left(E_{\alpha} / R T\right)^{\beta}$

The reaction rate is always improved by $2-3$ fold for every $10^{\circ} \mathrm{C}$ rise in temperature (Yang et al., 2010). Moreover, proteins in EPS are actually extracellular enzymes which might enhance sludge solubilization with increase of temperature. It should be mentioned that Guan et al. (2012) found that heating treatment had very limited influence on sludge EPS at the temperatures less than $55^{\circ} \mathrm{C}$, so the potential effects of temperature on sludge solubilization was marginal in the absence of enzymes addition.

As shown in Fig. 3, the curve of change in concentration of different EPS fractions reached the equilibrium after around $3 \mathrm{~h}$ of reaction. Again, the variation in EPS components can be fitted well with pseudo-first-order kinetic model, which was in agreement with the report of Yang et al. (2010). The reaction rates of SEPS, LBEPS and TB-EPS were $0.146,0.191$ and $-0.162 \mathrm{~h}^{-1}$ for protease and $0.306,0.358$ and $-0.192 \mathrm{~h}^{-1}$ for $\alpha$-amylase, thereby the production for LB-EPS was faster than that of SEPS. The process of enzymatic hydrolysis can be divided into three steps: (1) adsorption of hydrolytic enzymes on sludge surface; (2) diffusion of enzymes from out-layer to interior of sludge floc; (3) hydrolytic conversion of macromolecular substances (protein and polysaccharide). Feng 


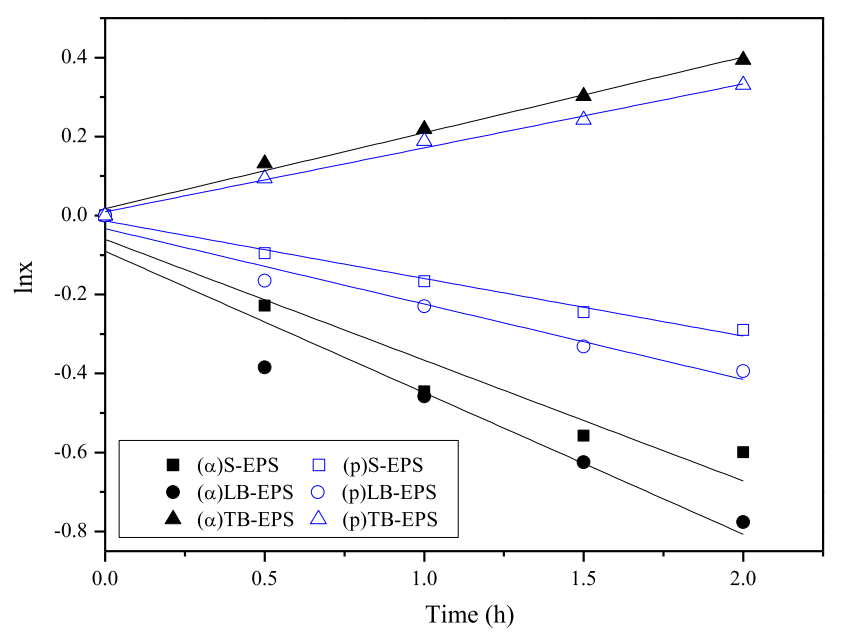

Fig. 4. Relationship between $\ln x$ and time during sludge hydrolysis.

et al. (2009) suggested that solubilization of particulate organic matters was the rate-limiting reaction of whole conversion from sludge particles to short-chain fatty acids. In the hydrolysis reaction stage, large protein was firstly decomposed into polypeptide and amino acids, which then converted into ammonium and organic acids; while the polysaccharide would be hydrolyzed into monosaccharide and even reducing sugars (Ji and Brune, 2005). The decomposition of protein-like substances can be confirmed by the increase in ammonium concentration in sludge bulk. As depicted in Fig. S2 of SI, change in ammonia concentration in sludge supernatant showed a similar pattern with that of SEPS concentration, protein and polysaccharide. After $5 \mathrm{~h}$ of reaction, the ammonium concentration was increased from $23.24 \mathrm{mg} \mathrm{L}^{-1}$ to $63.02 \mathrm{mg} \mathrm{L}^{-1}$ for protease and $245.65 \mathrm{mg} \mathrm{L}^{-1}$ for $\alpha$-amylase treatment.

3-DEEM method is widely used for characterization of natural organic matters in various water bodies with the advantages of high sensitivity and selectivity (Henderson et al., 2009). According to the report of Sheng and Yu (2006), fluorescence intensity of EEM could be used to measure EPS content as dissolve organic carbon (DOC) content in samples was less than $10 \mathrm{mg} \mathrm{L}^{-1}$. As depicted in Fig. S3 in SI, three dimensional fluorescence spectrum is divided into five major regions, which are soluble microbial byproducts (tryptophan-like protein), aromatic protein I, aromatic protein II, humic acid and fulvic acid respectively (Chen et al., 2003). Three dominant peaks were detected in all EPS fractions with the enzymatic hydrolysis: Peak A at excitation/emission (Ex/Em) of 275/335 (tryptophan-like protein), Peak B at Ex/Em of 225/310 (aromatic protein I) and Peak C at Ex/Em of 220/345 (aromatic protein II). Figs. S4 and S5 showed that fluorescent signals of all three peaks in SEPS and LB-EPS were intensified during reaction, while that of TBEPS was weakened. For instance, the fluorescent intensities of Peaks A, B and C were increased from $122.5,158.9$ and 227.6 to 342.4, 542.1 and 604.5 respectively after amylase treatment (Fig. 5). This observation was consistent with Lowry-Folin analysis. At the same time, no obvious change in fluorescence signals of humic and fulvic substances was detected, suggesting that enzymatic hydrolysis treatment had rather limited effect on these two substances.

\subsection{Sludge solubilization with compound enzymes}

Generally, most of biological enzymes are characterized by having a high degree of specificity, a specific enzyme is only able to catalyze for a defined substrate (Zhou et al., 2009). Meanwhile, protein and polysaccharide are the main components of sludge EPS in despite of its complexity (Roman et al., 2006). Therefore, the combined enzymatic hydrolysis (protease and amylase) was used to further enhance sludge solubilization efficiency. It can be seen from Fig. 6 (a) that the compound enzymes treatment performed better than single enzyme in sludge solubilization in terms of SEPS and LB-EPS. Furthermore, the addition mode had a significant influence on sludge lysis. $\alpha$-amylase + protease was more effective in solubilization than other two addition modes (protease $+\alpha$ amylase or simultaneous addition). This was because that the protein is the major component of $\alpha$-amylase (Kurosawa et al., 2006), whose activity was very likely to be inhibited due to hydrolysis in presence of protease (Jung et al., 2002). Especially, the release of polysaccharide in protease $+\alpha$-amylase treatment was much lower than other two addition modes and even single $\alpha$ amylase treatment (see in Fig. 6(c)). Initially, the sludge EPS was solubilized with amylase addition, and then pre-dissolved substrates could make a more sufficient contact with protease, which improved whole sludge hydrolysis efficiency.

\subsection{Effect of chemical re-flocculation on sludge properties}

\subsubsection{Effect of chemical re-flocculation on sludge dewatering performance}

Sludge dewaterabilty can be reflected by filtration rate and cake solid content. According to the equation of SRF:

$\frac{t}{V}=b V+a$

Where $b$ value is negatively linear with filtration rate. Bigger $b$ value means lower filtration rate.

It was observed from Fig. 7 that sludge filtration rate was significantly decreased after enzymatic treatment. Our previous studies suggested that soluble EPS component was the major factor affecting sludge filtration behavior, and high soluble EPS content, especially protein, was detrimental to filtration rate (Zhang et al., 2014, 2015a, 2015b). As mentioned above, protein and polysaccharide in bound EPS was effectively solubilized and released into the sludge bulk under enzymatic hydrolysis, thereby the sludge treated with enzymes was more resistant to filtration (Mikkelsen and Keiding, 2002).

Addition of inorganic coagulants cannot only reconstruct floc structure through bridging, but remove the soluble EPS in sludge bulk, especially macromolecule organic compounds by adsorption process of hydrolyzed products (Niu et al., 2013). The

Table 3

Reaction rate of different EPS fractions under enzymatic hydrolysis.

\begin{tabular}{llr}
\hline Enzymes & Dynamic equation & Rate constants $K_{h}\left(\mathrm{~h}^{-1}\right)$ \\
\hline Protease (S-EPS) & $\mathrm{y}=-0.146 \times-0.014$ & 0.146 \\
Protease (LB-EPS) & $\mathrm{y}=-0.191 \times-0.033$ & 0.191 \\
Protease (TB-EPS) & $\mathrm{y}=0.162 \times+0.010$ & -0.162 \\
$\alpha$-amylase (S-EPS) & $\mathrm{y}=-0.306 \times-0.061$ & 0.306 \\
$\alpha$-amylase (LB-EPS) & $\mathrm{y}=-0.358 \times-0.090$ & 0.99 \\
$\alpha$-amylase (TB-EPS) & $\mathrm{y}=0.192 \times+0.018$ & 0.96 \\
\hline
\end{tabular}



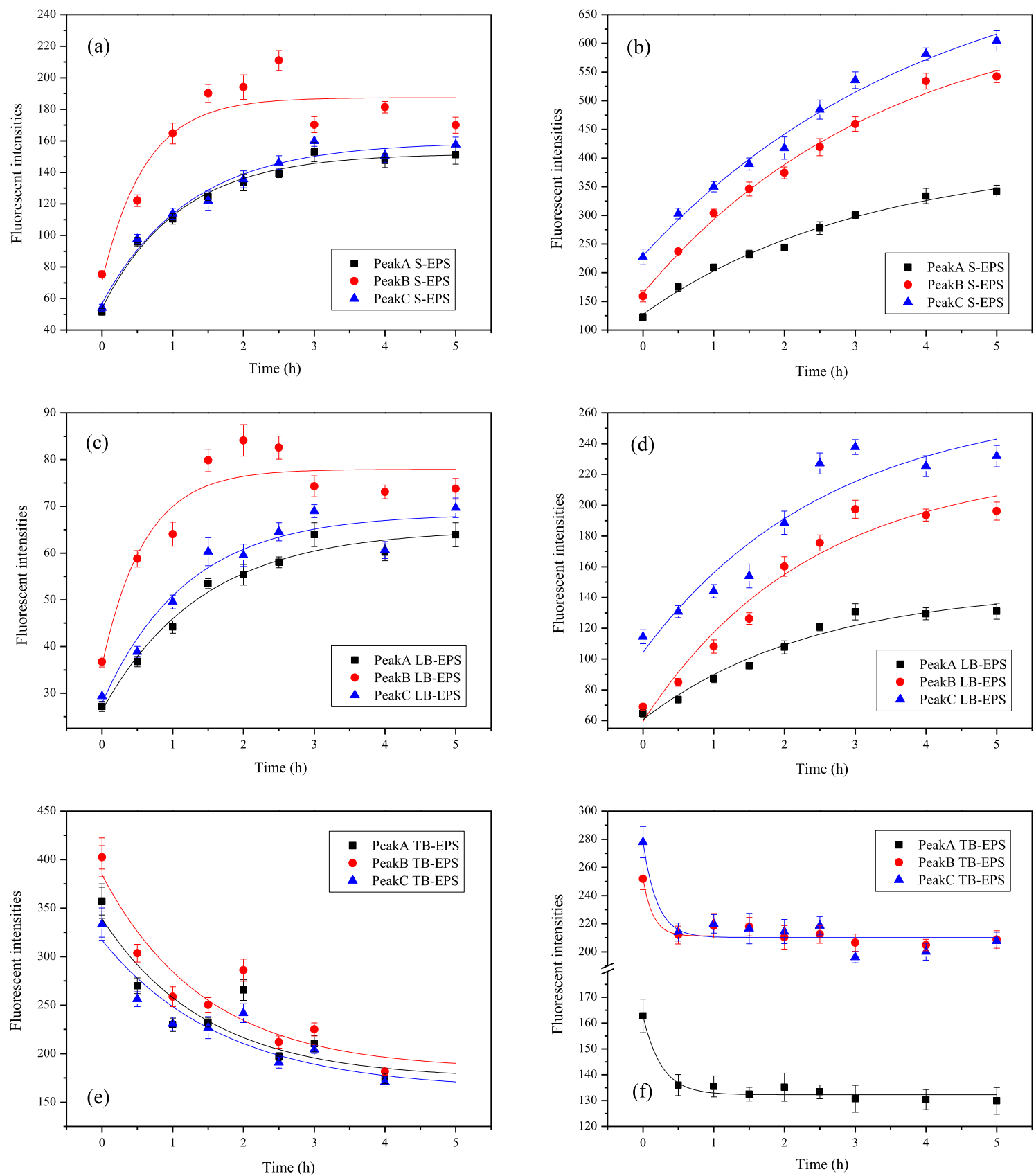

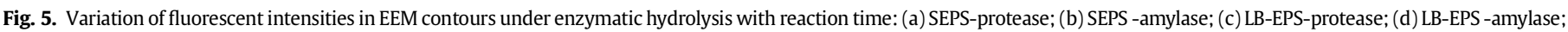
(e) TB-EPS-protease; (f) TB-EPS -amylase (Dosage of enzymes $=150 \mathrm{mg} / \mathrm{g}$; hydrolysis temperature of protease and amylase were 45 and $55^{\circ} \mathrm{C}$; EPS samples were diluted by 200 times).

macromolecule biopolymers were believed to be the major factor affecting sludge filtration behavior (Facchini et al., 2014). For the sludge treated with enzymes, both of filtration rate and cake solid content were improved with increasing dosage of inorganic salt coagulants. The optimal dosage of $\mathrm{FeCl}_{3}$ and $\mathrm{PACl}$ was $15 \%$ (g/gTSS), and the $b$ value was reduced from 1.78 to 0.17 for $\mathrm{PACl}$ and 0.1 for $\mathrm{FeCl}_{3}$. At the same time, sludge filtration property was very near to the sludge without enzymatic pretreatment, while the cake moisture reduction was favored after addition of enzymes. The cake moisture content was $82.6 \%$ for $\mathrm{PACl}$ and $81.5 \%$ for $\mathrm{FeCl}_{3}$ under enzymatic treatment, which was lower than that without addition of enzymes.

It was noted that $\mathrm{FeCl}_{3}$ performed better than $\mathrm{PACl}$ in improving sludge filterability and cake solid content. Since the floc strength played an important role in sludge filtration dewatering process, high floc strength was always favored to filtration. According to report of Niu et al. (2013), the ferric ions exhibited higher affinity to EPS (especially protein-like substances), hence the sludge floc conditioned with ferric ions was denser than that of formed from $\mathrm{PACl}$ conditioning, resulting in a higher filtration rate.

\subsubsection{Impact of chemical re-flocculation on sludge floc morphology}

Fig. 8 presented that for the original sludge, sludge floc size was increased under chemical flocculation, and reached equilibrium of $134.33 \mu \mathrm{m}$ and $97.97 \mu \mathrm{m}$ when dosage of $\mathrm{PACl}$ and $\mathrm{FeCl}_{3}$ were $5 \%$ and $10 \%$. For the sludge after enzymatic treatment, the floc increased to $103.18 \mu \mathrm{m}$ and $59.66 \mu \mathrm{m}$ when dosage of both $\mathrm{PACl}$ and $\mathrm{FeCl}_{3}$ were 20\%. By comparison, the floc formed from $\mathrm{PACl}$ 

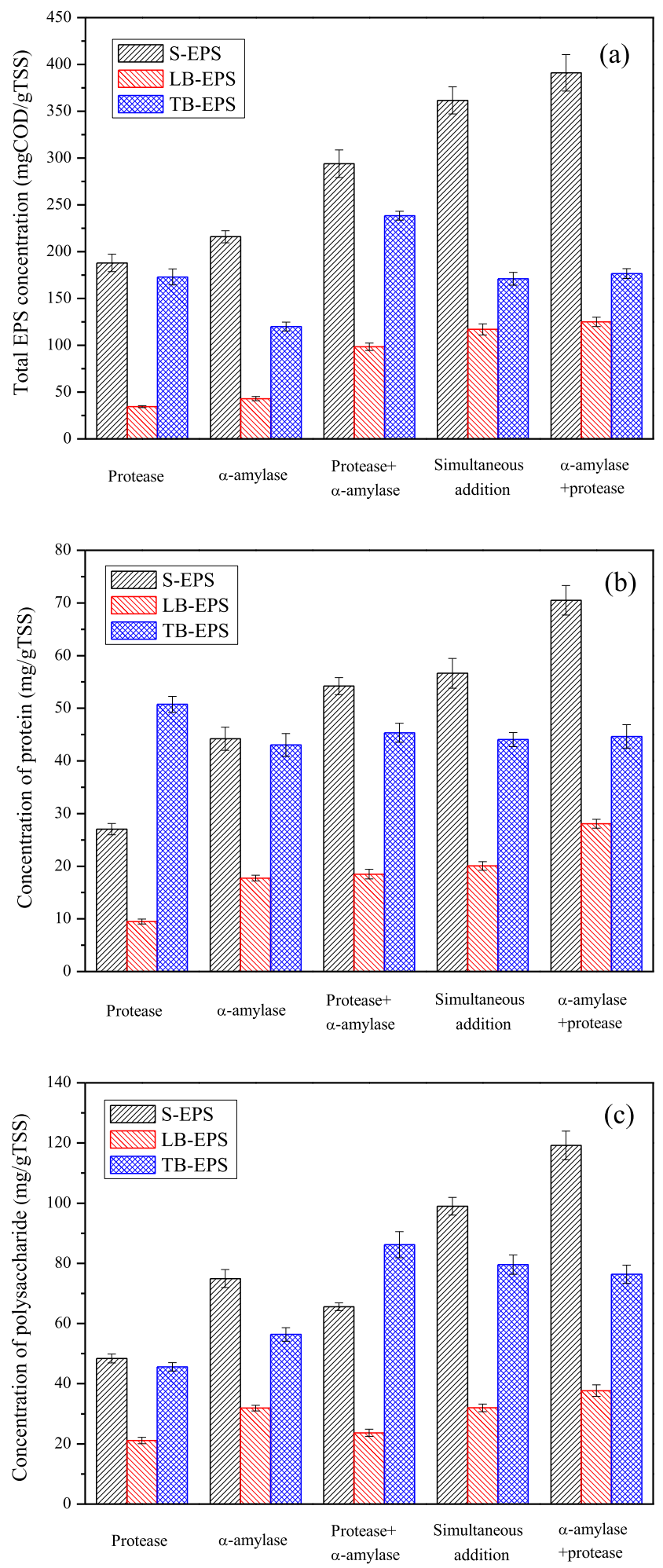

Fig. 6. Addition mode of two enzymes on sludge solubilization efficiency: (a) total EPS content; (b) protein; (c) polysaccharide (The dosage of protease and $\alpha$-amylase was $150 \mathrm{mg} / \mathrm{g})$.

coagulation was larger than that of $\mathrm{FeCl}_{3}$ at low coagulants dosage, while opposite trend was observed at high dose. PACl is typical inorganic polymer flocculants, it had more abundant binding sites with sludge particles and thereby producing larger flocs. However, the PACl generally was more positively charged, so overdosed PACl
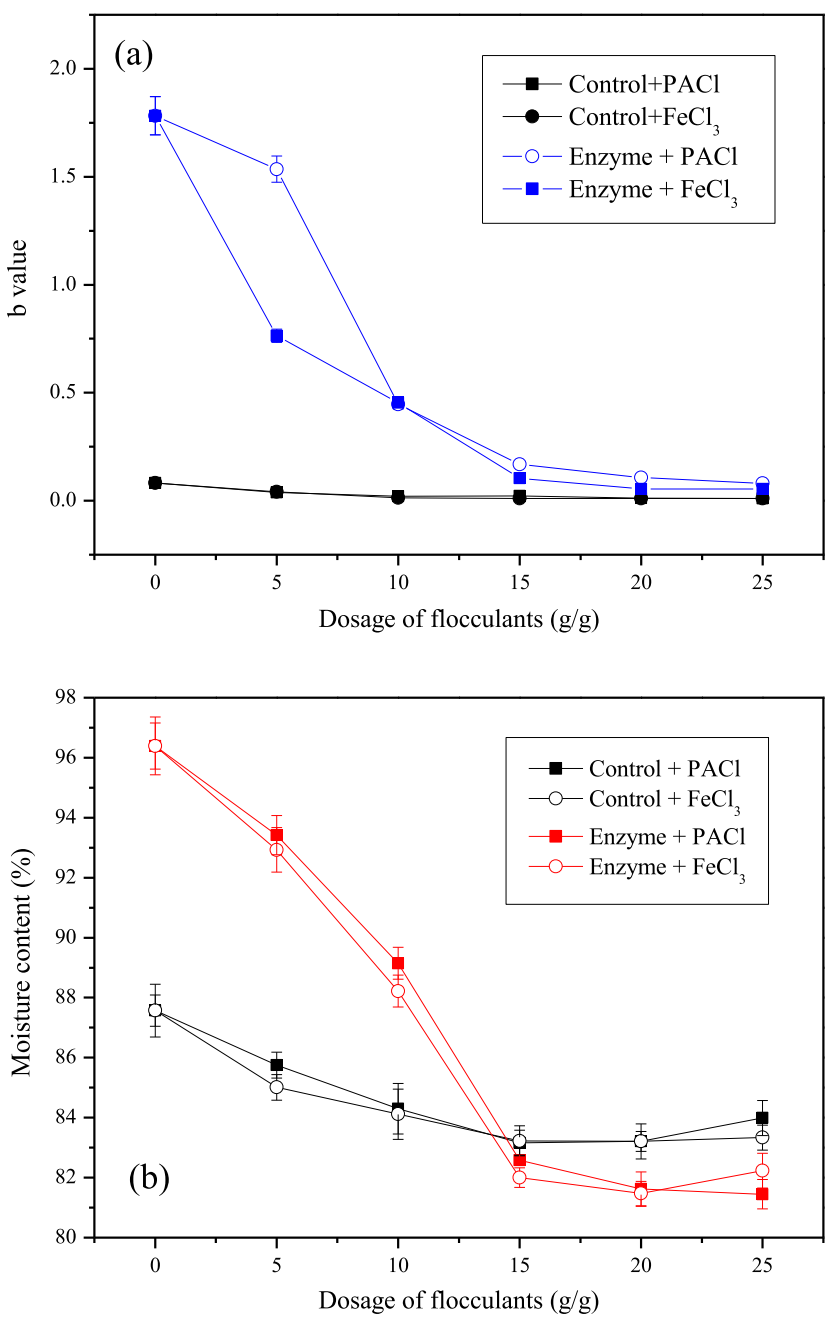

Fig. 7. Effect of coagulants dosage on sludge (a) b value (filtration rate); (b) cake moisture content (The dosage of protease and $\alpha$-amylase was $150 \mathrm{mg} / \mathrm{g}$ ).

was more likely to result in colloidal re-stabilization and prevent further aggregation of sludge particles. It should be noted that coagulated sludge floc was smaller after enzymatic pretreatment. It was very likely that organic matters with high molecular weight (MW) in sludge EPS was converted into smaller organic compounds, and alleviated the electrostatic and hydrophobic interactions between hydrolyzed products of coagulants and EPS (Lee and Liu, 2001). As shown in Fig. S7, through enzymatic treatment (compound or single), original sludge floc was destroyed, and the particle became smaller, which was in agreement with the floc size analysis. Afterward, sludge floc grew and aggregated after addition of inorganic coagulants, and edge of sludge flocs were more uniform, revealing that more compact floc formed after chemical coagulation.

\subsubsection{Influence of chemical flocculation on SEPS}

As shown in Fig. 9 (a), the dosage for inorganic coagulants were $5 \%$ and $20 \%$, the soluble COD (SCOD) content reached the minimum for original and composite enzyme treated sludge respectively. The SCOD concentration was increased with further increasing dosage of inorganic coagulants. This result could be attributed to restabilization of colloidal system in the presence of overdosed coagulants. It is worthy to note that since the charge density of $\mathrm{PACl}$ was higher than $\mathrm{FeCl}_{3}$, the phenomenon was more apparent for 


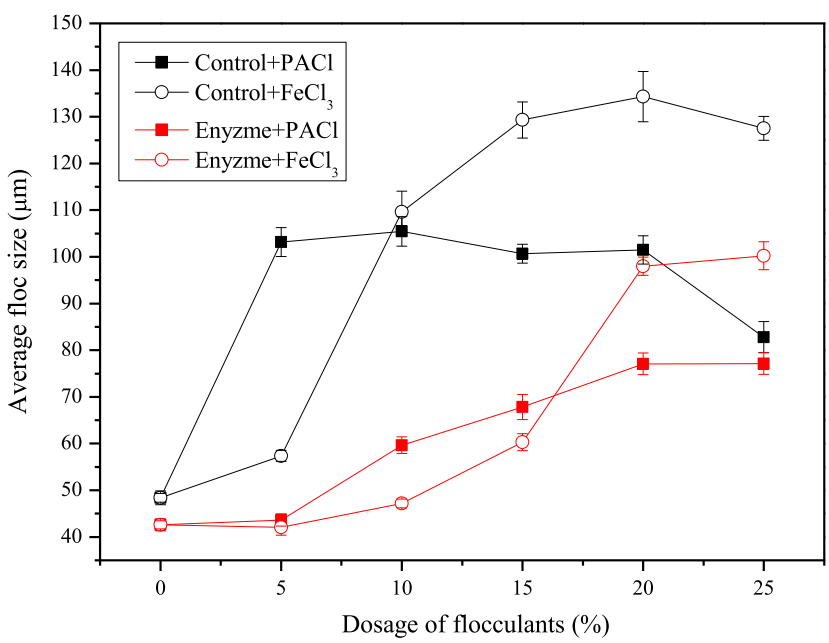

Fig. 8. Impact of coagulants dosage on sludge particle size $\left(d_{0.5}\right)$ (The dosage of protease and $\alpha$-amylase was $150 \mathrm{mg} / \mathrm{g}$ )

PACl. Fig. 9 (b) clearly presented that $\mathrm{FeCl}_{3}$ was more effective in removing tryptophan- and aromatic-proteins than PACl. This is consistent with the report of Yu et al. (2008), who also stated that ferric ions exhibited higher affinity to protein-like substances. In
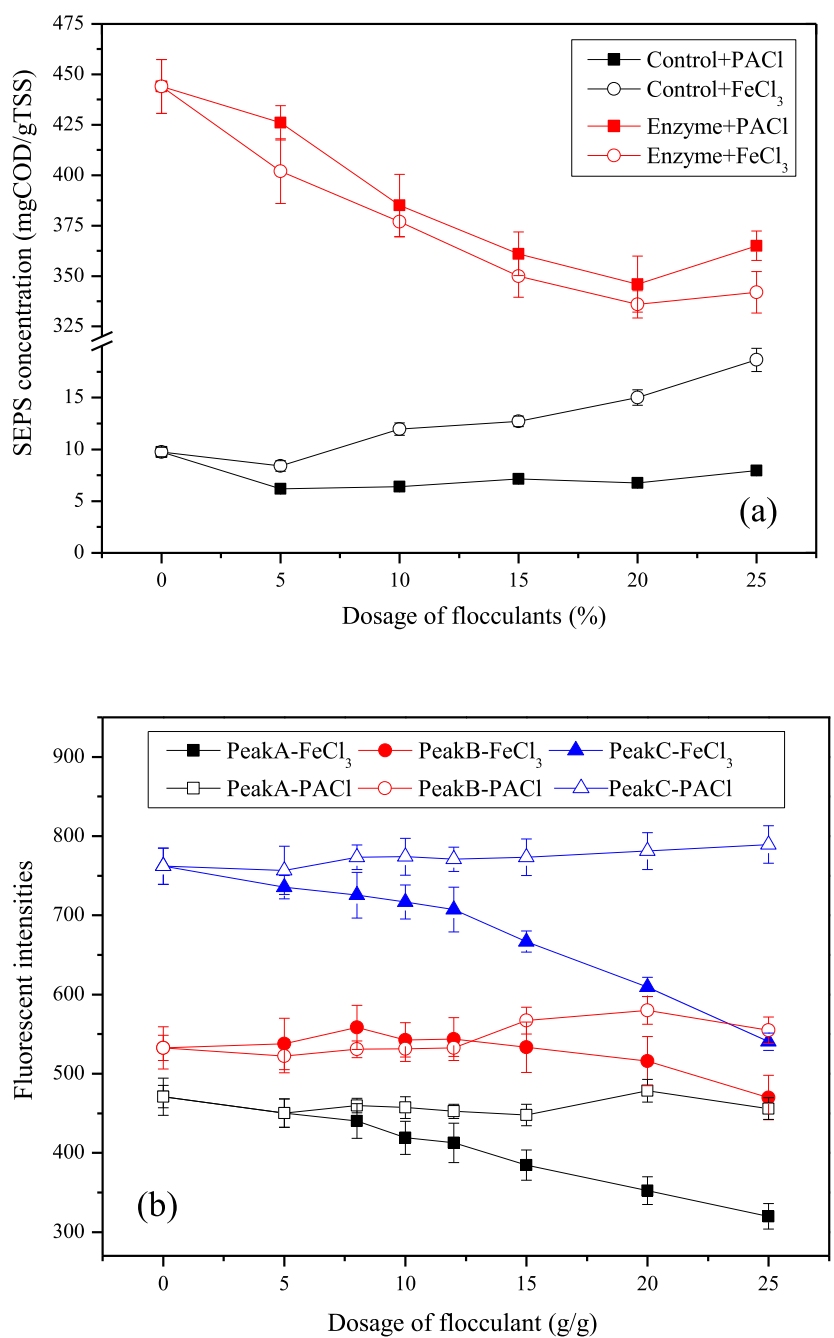

Fig. 9. Variation in chemical characteristics of SEPS chemical re-flocculation with different inorganic coagulants: (a) SEPS content; (b) fluorescent intensities. our previous studies, it was found that protein-like substances were the deciding factor of sludge filterability (Zhang et al., 2015b). Thus, this is another reason for higher performance of ferric iron in sludge dewaterability improvement.

\section{Conclusion}

This study attempted to use the enzymatic pretreatment to improve drying performance in sludge filtration dewatering process.

- Sludge filtration performance was deteriorated due to release of a large amount of biopolymers after enzymatic treatment. $\alpha$ amylase exhibited better performance than protease in sludge solubilization. Moreover, EPS was more extractable after enzymatic treatment, producing looser floc structure.

- The change in EPS components can be fitted well with pseudofirst-order kinetic model. The reaction rates of SEPS, LB-EPS and TB-EPS were $0.146,0.191$ and $-0.162 \mathrm{~h}^{-1}$ for protease and 0.306 , 0.358 and $-0.192 \mathrm{~h}^{-1}$ for $\alpha$-amylase.

- The feeding modes of enzymes had a significant influence on sludge lysis efficiency under compound enzymes treatment. $\alpha$ amylase + protease was more effective in solubilization than other two addition modes (protease $+\alpha$-amylase or simultaneous addition).

- Both of filtration rate and cake solid content were improved with increasing dosage of inorganic salt coagulants. The optimal dosage of $\mathrm{FeCl}_{3}$ and $\mathrm{PACl}$ was $15 \%$ (g/gTSS), the cake moisture reduction was improved after enzymatic pretreatment.

\section{Acknowledgment}

This study was financially supported by the State Water Project for Integrated Water Supply Sludge Quality and Depth of Dewatering Technology (2012ZX07408001-05) and National Natural Science Foundation in China (51025830, 41201498 and 51178360).

\section{Appendix A. Supplementary data}

Supplementary data related to this article can be found at http:// dx.doi.org/10.1016/j.watres.2015.06.026.

\section{References}

APHA, A., 1998. WEF. Standard Methods for the Examination of Water and Wastewater, 20th ed. American Public Health Association, American Water Work Association, Water Environment Federation, Washington DC, p. 252.

Ayol, A., 2005. Enzymatic treatment effects on dewaterability of anaerobically digested biosolids-I: performance evaluations. Process Biochem. 40 (7), 2427-2434.

Bonilla, S., Tran, H., Allen, D.G., 2015. Enhancing pulp and paper mill biosludge dewaterability using enzymes. Water Res. 68, 692-700.

Chen, W., Westerhoff, P., Leenheer, J.A., Booksh, K., 2003. Fluorescence excitation emission matrix regional integration to quantify spectra for dissolved organic matter. Environ. Sci. Technol. 37 (24), 5701-5710.

Dignac, M.F., Urbain, V., Rybacki, D., Bruchet, A., Snidaro, D., Scribe, P., 1998. Chemical description of extracellular polymers: implication on activated sludge floc structure. Water Sci. Technol. 38 (8-9), 45-53.

Dursun, D., Turkmen, M., Abu-Orf, M., Dentel, S., 2006. Enhanced sludge conditioning by enzyme pre-treatment: comparison of laboratory and pilot scale dewatering results. Water Sci. Technol. 54 (5), 33-41.

Facchini, L., Bellin, A., Toro, E.F., 2014. A mathematical model for filtration and macromolecule transport across capillary walls. Microvasc. Res. 94, 52-63.

Feng, L.Y., Yan, Y.Y., Chen, Y.G., 2009. Kinetic analysis of waste activated sludge hydrolysis and short-chain fatty acids production at pH 10. J. Environ. Sci. 21 (5), 589-594.

Frolund, B., Palmgren, R., Keiding, K., Nielsen, P.H., 1996. Extraction of extracellular polymers from activated sludge using a cation exchange resin. Water Res. 30 (8), 1749-1758.

Guan, B.H., Yu, J., Fu, H.L., Guo, M.H., Xu, X.H., 2012. Improvement of activated sludge dewaterability by mild thermal treatment in $\mathrm{CaCl} 2$ solution. Water Res. 
46 (2), 425-432.

Henderson, R.K., Baker, A., Murphy, K.R., Hamblya, A., Stuetz, R.M., Khan, S.J., 2009 Fluorescence as a potential monitoring tool for recycled water systems: a review. Water Res. 43 (4), 863-881.

Higgins, M.J., Novak, J.T., 1997. Characterization of exocellular protein and its role in bioflocculation. J. Environ. Eng. 123 (5), 479-485.

Houghton, J.I., Quarmby, J., Stephenson, T., 2001. Municipal wastewater sludge dewaterability and the presence of microbial extracellular polymer. Water Sci. Technol. 44 (2-3), 373-379.

Ji, R., Brune, A., 2005. Digestion of peptidic residues in humic substances by an alkali-stable and humic-acid-tolerant proteolytic activity in the gut of soilfeeding termites. Soil Biol. Biochem. 37 (9), 1648-1655.

Jung, J., Xing, X.H., Matsumoto, K., 2002. Recoverability of protease released from disrupted excess sludge and its potential application to enhanced hydrolysis of proteins in wastewater. Biochem. Eng. J. 10 (1), 67-72.

Kurosawa, K. Hosaka, T., Tamehiro, N., Inaoka, T., Ochi, K., 2006. Improvement of alpha-amylase production by modulation of ribosomal component protein S12 in Bacillus subtilis 168. Appl. Environ. Microbiol. 72 (1), 71-77.

Lee, C.H., Liu, J.C., 2001. Sludge dewaterability and floc structure in dual polymer conditioning. Adv. Environ. Res. 5 (2), 129-136.

Li, X., Yang, S., 2007. Influence of loosely bound extracellular polymeric substances (EPS) on the flocculation, sedimentation and dewaterability of activated sludge. Water Res. 41 (5), 1022-1030.

Liu, H., Yang, J.K., Zhu, N.R., Zhang, H., Li, Y., He, S., Yang, C.Z., Yao, H., 2013. A comprehensive insight into the combined effects of Fenton's reagent and skeleton builders on sludge deep dewatering performance. J. Hazard. Mater. 258, 144-150.

Liu, Y., Fang, H.H.P., 2003. Influences of extracellular polymeric substances (EPS) on flocculation, settling, and dewatering of activated sludge. Crit. Rev. Anal. Chem. 33 (3), 237-273.

Liyun Ge, H.W., Luming, Ma, 2006. The optimization of extracellular polymer physical extraction process. Environ. Chem. 25 (6), 22-725.

Mikkelsen, L.H., Keiding, K., 2002. Physico-chemical characteristics of full scale sewage sludges with implications to dewatering. Water Res. 36 (10), $2451-2462$.

Murthy, S.N., Novak, J.T., 1999. Factors affecting floc properties during aerobic digestion: implications for dewatering. Water Environ. Res. 71 (2), 197-202.

Neyens, E., Baeyens, J., 2003. A review of classic Fenton's peroxidation as an advanced oxidation technique. J. Hazard. Mater. 98 (1-3), 33-50.

Neyens, E., Baeyens, J., Dewil, R., De heyder, B., 2004. Advanced sludge treatment affects extracellular polymeric substances to improve activated sludge dewatering. J. Hazard. Mater. 106 (2-3), 83-92.

Niu, M.Q., Zhang, W.J., Wang, D.S., Chen, Y., Chen, R.L., 2013. Correlation of physicochemical properties and sludge dewaterability under chemical conditioning using inorganic coagulants. Bioresour. Technol. 144, 337-343.

Poxon, T.L., Darby, J.L., 1997. Extracellular polyanions in digested sludge: measurement and relationship to sludge dewaterability. Water Res. 31 (4), 749-758.
Ramesh, A., Lee, D.-J., Hong, S., 2006. Soluble microbial products (SMP) and soluble extracellular polymeric substances (EPS) from wastewater sludge. Appl. Microbiol. Biotechnol. 73 (1), 219-225.

Raynaud, M., Vaxelaire, J., Olivier, J., Dieude-Fauvel, E., Baudez, J.-C., 2012 Compression dewatering of municipal activated sludge: effects of salt and $\mathrm{pH}$. Water Res. 46 (14), 4448-4456.

Roman, H.J., Burgess, J.E., Pletschke, B.I., 2006. Enzyme treatment to decrease solids and improve digestion of primary sewage sludge. Afr. J. Biotechnol. 5 (10) 963-967.

Sesay, M.L., Ozcengiz, G., Sanin, F.D., 2006. Enzymatic extraction of activated sludge extracellular polymers and implications on bioflocculation. Water Res. 40 (7) 1359-1366.

Sheng, G.P., Yu, H.Q., 2006. Characterization of extracellular polymeric substances of aerobic and anaerobic sludge using three-dimensional excitation and emission matrix fluorescence spectroscopy. Water Res. 40 (6), 1233-1239.

Thomas, L., Jungschaffer, G., Sprössler, B., 1993. Improved sludge dewatering by enzymatic treatment. Water Sci. Technol. 28 (1), 189-192.

Tokumura, M., Sekine, M., Yoshinari, M., Znad, H.T., Kawase, Y., 2007. Photo-Fenton process for excess sludge disintegration. Process Biochem. 42 (4), 627-633.

Vaxelaire, J., Cezac, P., 2004. Moisture distribution in activated sludges: a review. Water Res. 38 (9), 2215-2230.

Yang, Q., Luo, K., Li, X.M., Wang, D.B., Zheng, W., Zeng, G.M., Liu, J.J., 2010. Enhanced efficiency of biological excess sludge hydrolysis under anaerobic digestion by additional enzymes. Bioresour. Technol. 101 (9), 2924-2930.

Yu, G.H., He, P.J., Shao, L.M., He, P.P., 2008. Stratification structure of sludge flocs with implications to dewaterability. Environ. Sci. Technol. 42 (21), 7944-7949.

Yu, J., Guo, M.H., Xu, X.H., Guan, B.H., 2014. The role of temperature and $\mathrm{CaCl} 2$ in activated sludge dewatering under hydrothermal treatment. Water Res. 50, 10-17.

Zhang, W., Peng, S., Xiao, P., He, J., Yang, P., Xu, S., Wang, D., 2015a. Understanding the evolution of stratified extracellular polymeric substances in full-scale activated sludges in relation to dewaterability. RSC Adv. 5 (2), 1282-1294.

Zhang, W., Xiao, P., Liu, Y., Xu, S., Xiao, F., Wang, D., Chow, C.W., 2014. Understanding the impact of chemical conditioning with inorganic polymer flocculants on soluble extracellular polymeric substances in relation to the sludge dewaterability. Sep. Purif. Technol. 132 (20), 430-437.

Zhang, W., Yang, P., Xiao, P., Xu, S., Liu, Y., Liu, F., Wang, D., 2015b. Dynamic variation in physicochemical properties of activated sludge floc from different WWTPs and its influence on sludge dewaterability and settleability. Colloids Surf. A 467, 124-134.

Zhou, J., Wang Y.H., Chu, J., Luo, L.Z, Zhuang Y.P., Zhang, S.L., 2009. Optimization of cellulase mixture for efficient hydrolysis of steam-exploded corn stover by statistically designed experiments. Bioresour. Technol. 100 (2), 819-825.

Zhu, J., Peng, Y., Li, X., Su, G., Wang, S., 2013. Change and mechanism of sludge dewaterability during alkaline fermentation. CIESC J. 64 (11), 4210-4215. 